\title{
Forecasting Knife Homicide Risk from Prior Knife Assaults in 4835 Local Areas of London, 2016-2018
}

\author{
John Massey, et al. [full author details at the end of the article]
}

Published online: 14 April 2019

(C) The Author(s) 2019

\begin{abstract}
Research Question How accurately can all recorded locations of 97 knife homicides in one year be forecast across all 4835 Lower Layer Super Output Areas (LSOAs) of London, based only upon all 3506 known locations of nonfatal knife injury assaults in the preceding year?
\end{abstract}

Data All recorded "knife crimes" in the Metropolitan Police Service (MPS) area of London in the financial year 2016-2017 (year 1) were manually reviewed to identify all 3506 reported locations of knife-enabled (KE) but nonfatal injuries, as distinct from other events digitally coded as "knife crimes", such as displaying, threatening with, or carrying knives. All KE homicides in 2017-2018 (year 2) were then added to the database.

Methods Each KE injury assault in year 1 was classified for occurrence in one of London's 4835 LSOAs. The total $N$ of such crimes within each LSOA was summed across all records to divide all LSOAs into seven categories of frequency of KE injury assaults in 2016/2017: 0, 1, 2, 3, 4, 5, and 6 or more. We then divided the $N$ of LSOAs in each category in 2016/2017 (year 1) into the total $N$ of knife homicides in 2017/2018 (year 2). False positives, false negatives, and percentage of homicides targeted were calculated for six different targeting plans.

Findings Over two thirds (69\%) of KE homicides in 2017/2018 (year 2) occurred in just 67 (1.4\%) of all 4835 LSOAs, comprising 3.3\% of the 2048 LSOAs that had had one or more of the $3506 \mathrm{KE}$ injury assaults mapped in 2016/2017 (year 1). The proportion of LSOAS with a KE homicide in year 2 was higher where there were higher numbers of KE injury assaults per LSOA in year 1. Among LSOAs with zero assaults in year 1 , only $1 \%$ had a KE homicide in year 2 . Among LSOAs with six or more KE injury assaults in year $1,15 \%$ had a KE homicide in year 2 . While the risk of homicide was $1400 \%$ higher in the hottest spots of knife assaults than in the coolest spots, the absolute number of year two KE homicides in those hottest areas was only $6 \%$ of the total. All LSOAs with one or more year $1 \mathrm{KE}$ assaults had three times as much KE homicide risk than LSOAs with no year $1 \mathrm{KE}$ assaults. Targeting all 2048 areas that had one or more year $1 \mathrm{KE}$ assaults would have yielded a true positive rate of over $3 \%$ and covered $69 \%$ of actual homicide locations. The true negative rate for 2781 areas that would not have been targeted based on having no year $1 \mathrm{KE}$ injuries would have been $99 \%$. 
Conclusions Predicting which local areas are most likely to suffer knife-enabled homicides, based only on recent nonfatal knife injuries, can pinpoint risks of homicide in local areas that are up to $1400 \%$ higher than in most local areas, offering a range of strategies for resource allocation.

Keywords Homicide $\cdot$ Knives · Prediction · Knife assaults · Targeting accuracy $\cdot$ Hot spots . Lower Layer Super Output Areas · LSOA

\section{Introduction}

How predictable are the locations of knife homicide in London? That question is difficult to answer based on professional experience, given the rarity of homicides in any specific location. As Mark Jackson of the Metropolitan Police Service (2010) discovered, only 12\% (579) of all 4765 local census areas of London had any knifeenabled homicides over the 10 years from 2000 to 2010. Over 365 days from April 2017, our own study finds that only $1 \%$ of the 4835 local areas (2011 Census) had any of the locatable 97 knife-enabled (KE) homicides. Moreover, there were no local areas that had more than one such homicide, which means that there were no hot spots of repeated knife homicides that year (contra Sherman et al. 1989; Weisburd 2015).

There were, however, clearly identifiable hot spots of nonfatal KE assaults. It is these nonfatal knife crimes that provide a reliable, if far from perfect, basis for forecasting KE homicides over the time span of 1 year. Over two thirds (69\%) of all KE homicides in 2017/2018 (which this study calls "year 2") occurred in the 2048 local areas where one or more of the $3543 \mathrm{KE}$ assaults were reported to have occurred in London in "year 1" (2016/2017). Interspersed between those hot spots, at the same time, were 2787 areas that had zero nonfatal KE assaults in 2016/2017 (year 1), and only $1 \%$ of those had a KE homicide in year 2 .

Such rare events are difficult for any professional to forecast based on personal experience alone (Sutherland and Mueller-Johnson 2019). Even if police officers consult digitized crime records and maps, however, they would be misled by the failure of official statistics to count the precise behavior that kills: stabbing or cutting people with knives. Under current record-keeping systems, what the Office of National Statistics presents a wide array of crimes in which a knife was used: threats to kill, robbery, assaults without injury, etc. (ONS 2019). The only way to identify where victims of stabbing were stabbed nonfatally in England in 2019 is to read the full text of a narrative report, with no digital code available to indicate actual stabbings.

Yet it is the actual stabbing behavior that is critically important for the problem of KE homicide. Remarkably, the ratio of deaths per stabbing in London in 2016/2017 was 1 in 66 (see below), while in Chicago in 1965, it was almost identical at 1 in 55 (Zimring 1968). Given a large body of weapons crime research available in the USA (Wellford et al. 2005), our aim was to test the forecasting value of precisely counting the behavior most likely to cause death by knife.

Our objective in this article is to demonstrate whether comprehensive statistical analysis of where KE assaults have occurred in the recent past will help to forecast where KE homicides are most likely to occur in the near future. While we do not compare that forecasting method to the accuracy of forecasts based on qualitative 
intelligence, we note that there is presently no research evidence available on the accuracy of either method of forecasting murder. By testing the comprehensive datadriven approach over 2 years, we can at least set a benchmark of predictive accuracy for other methods to beat. We also hope to assess the value of a major investment in a rapid change of crime counting systems, in order to count, map, and analyze KE assaults separately and distinctly from all other knife crimes.

\section{A Digital Policing Strategy}

Such forecasts as we present here can become even more accurate if they are embedded into a digital policing strategy - one that uses ongoing data processing programs to update the city-wide homicide forecasts immediately upon new information being added to a forecasting model. Yet, we must recognize the substantial imitations of any forecasting of homicide risk by location. Even if we knew with $100 \%$ probability where homicides would happen in London during one of the 525,600 min a year, we would be greatly challenged to predict when they will occur across the possible targets of $525,600 \mathrm{~min} \times 4835$ local census areas, which is equal to 2.5 billion place minutes per year. On the other hand, if we define the challenge of evidence-based targeting as sending police to where they would be most likely to prevent homicide, a digital policing approach should offer great advantages over conventional policing. By using up-to-theminute data on well-tested predictors, police commanders could move resources immediately to where they may produce the greatest benefits in saving lives. That challenge is especially salient with homicides committed by concealed weapons, notably knives and guns.

What predictors might work best? A digital policing strategy, in the not-too-distant future, could monitor London's crime patterns in real time for daily forecasting of locations at the highest risk of a knife-enabled homicide. Many variables, from social media activity to the weather, could become part of a forecasting model, as discussed at a Ditchley Foundation conference chaired by Metropolitan Police Service (MPS) Commissioner Cressida Dick (Dick 2018). Yet, the entire concept of forecasting remains unfamiliar and often controversial, with frequent misunderstandings. Before a complex forecasting model is used to deploy police resources, police legitimacy would be well served by having a transparent, single-predictor basis for demonstrating the very great (and statistically predictable) differences in homicide risk levels from each local area to all others.

\section{Counting Near-Miss Murders}

The most fundamental starting point for predicting most kinds of rare events is nearmisses of those events, in which the highest harm level almost occurs but does not actually happen. In air traffic safety, the near-miss concept implies that no harm occurs at all, as when two planes almost collide but do not. In policing, however, the relationship between fatal and nonfatal violence has long been understood to comprise a near-miss to a fatal injury. Using such near-misses to forecast homicide, based on long-term patterns of prior assaults (Mohler 2014), has been shown to provide substantial improvements over short-term-only analyses, especially by using most recent data in combination with longer-term patterns. 


\section{Testing Tactics in Targeted Hot Spots}

Even daily updates of such forecasting, however, do not provide guidance on the particular police practices that should be employed in each high-risk location. Exactly what to do is, of course, a matter for testing, given reliable targeting of where to do it (Sherman 2013). Fortunately, in the case of weapon-enabled homicide, there is already a growing body of theory and evidence, albeit mostly from the USA. One theory dates to 1980, when two Harvard criminologists (Wilson 1980; Moore 1980) independently proposed that gun homicides could be reduced by focusing on widespread gun carrying by numerous gun carriers. The Harvard theory emerged shortly after the criminological perspective called routine activity theory (Cohen and Felson 1979), which itself built on the UK Home Office situational crime prevention literature (Mayhew et al. 1976), all of which stressed that opportunity is essential for committing a crime.

By focusing on concealed weapons as the proximate opportunity for committing most weapon-enabled homicides, the Harvard theorists suggested that police could deter decisions to carry weapons more readily than police could deter decisions to commit homicide. Wilson and Moore argued, in effect, that if illicit weapons are left at home for fear of arrest for illegal carrying, people inclined to use those weapons will have no opportunity to use them when encountering someone they might decide to attack. The deterrence of weapon carrying would thus block the opportunity to commit homicide, which would then reduce the frequency of homicide itself.

The evidence testing the Wilson-Moore theory has consistently supported its prediction. In a series of field tests in Kansas City (MO) (Sherman et al. 1995), Indianapolis (McGarrell et al. 2001), Pittsburgh (Cohen \& Ludwig 2003), and St. Louis (Rosenfeld et al. 2014), police consistently found support for the target-the-carrying strategy causing a reduction in murders or weapons injuries [see also Bogota and Cali in Colombia (Villaveces et al. 2000)]. Shootings of guns, measured by either deaths, hospital treatment, or crime reports, went down in the test sites of all of these studies, relative to untreated high-shooting areas, when police targeted high-harm areas with proactive patrols and stop-search strategies. According to a systematic review of most of this work (Koper and Mayo-Wilson 2006), not one test failed to find evidence that criminal weapon usage declined when police targeted weapon carrying - in hot spot areas where weapon crime was concentrated. In each US case, this strategy began with careful analysis of where weapon-enabled homicides were most likely to occur, and concluded with intensive proactive policing of weapon carrying in those areas.

\section{Do Near-Miss Injuries Predict Knife Homicide in London?}

That proactive US strategy has been at the core of a long debate over stop and search in England and Wales. In general, however, the UK debate has neglected any discussion of two kinds of evidence. One is the evidence that stop-and-search works best when it is confined to a tiny fraction of a city where weapons crimes are most likely to occur. The US evidence showed success of using stop and search, but not just anywhere. It is all tested on precisely targeted crime hot spots, as distinct from an undifferentiated use of that tactic across any and all locations. The other evidence missing in the UK debate has been research on whether geographic concentrations of weapon-enabled homicides even exist in the UK-a crucial 
premise for a policy of limiting the most intrusive policing to that tiny fraction of any city in which a risk of weapon-enabled homicide is highest.

This article contributes to that second area of evidence missing from the UK debate. It is only a first, but crucial, step towards a more refined digital policing strategy for preventing homicide. This step provides what appears to be the first UK test of the hypothesis that any form of homicide can be predicted in micro-areas on the basis of prior near-misses, or nonfatal assaults using the same weapon as the fatal assaults. By using 4835 small census areas across London to pinpoint where knife carrying most commonly leads to nonfatal woundings, the article assesses whether the locations of those KE woundings can provide more accurate forecasts of future KE homicide locations.

\section{Targeting Lower Layer Super Output Areas}

In adopting this approach, this study builds upon the work of Metropolitan Police Service Detective Superintendent Mark Jackson (2010), whose Cambridge M.St. thesis first analyzed London's homicide distribution within relatively small locations called Lower Layer Super Output Areas (LSOAs). These areas, like US Census tracts, are defined by the decennial UK Census of the Office of National Statistics. These geographical areas, in London in 2011, were home to an average of 1722 people each (based on the last census) and may be as small as 200 metres square. Nationally, each LSOA had 400 to 1200 households (Office of National Statistics 2011, 2019).

What Jackson (2010) showed with these areas was not just the concentration of knifeenabled homicide in a small number of these areas (with $88 \%$ of LSOAs across London free from any knife homicides over 10 years). He also showed that these "homicide hotspots" are themselves geographically very small. That size means that, in theory, KE homicide can be more effectively prevented by concentrating police resources at higher levels of blue uniforms or police cars per square foot (Sherman 2013).

While the MPS in 2019 is reorganizing 32 separately run operational command units (OCUs) into only 12, far larger, basic command units (BCUs), it becomes even more important for BCU commanders to have micro-level data on each LSOA. Jackson's (2010) discovery that only $6 \%$ of LSOAs accounted for $42 \%$ of all homicides over 10 years showed the serious limitation of using large areas as operational units of analysis. Most parts of the 32 large OCUs had no homicide at all for a decade. Targeting at the LSOA level, however, revealed patterns of homicides recurring in many LSOAs year after year.

The purpose of such analysis is not a passive prediction of future homicide trends. Rather, our aim is to show how useful it would be for digital policing to produce regularly updated maps of locations where homicide is most likely to occur in the near future. This should, in principle, enable police leaders to target, and even test, more efficient and effective measures to prevent homicides with digital policing forecasts.

\section{Research Questions}

This article addresses a small but vital subset of a larger analysis of homicide across London in 2008-2018 reported in the first author's M.St. thesis (Massey 2018). Our 
present focus is on how the key elements of that analysis can be turned into decision support tools for operational policing. The central question is how best to forecast and target locations where most KE homicides are most likely to occur.

That broad question has many potential answers. This study focuses on whether one of the most powerful answers is to look closely at near-miss homicides as a powerful predictor of completed homicides. Our focus is purposely limited to KE homicides and near-misses because they have risen most rapidly in recent years. They are also homogenous group that offers more reliability in predictions than the full diversity of all homicides. While many other predictors could ultimately contribute to a daily forecasting model, we limit the present analysis so that a wide audience can understand how purely objective criteria can be used for targeting police resources to save lives.

These are the four specific research questions for this article:

1. Does the prevalence of KE homicide across LSOAs in a given year (year 2) predictably increase with higher frequency of KE assaults in an LSOA in the prior year (year 1)?

2. If so, how much higher is the highest risk level for KE homicide compared to the lowest risk level, in terms of the likelihood that any KE homicide occurs in year 2?

3. What is the level of "sensitivity" or true positive homicide prediction rate from a decision to target LSOAs with extra policing resources at different levels of KE assaults?

4. What is the level of "specificity" or true negative rate from a decision to target LSOAs with extra policing resources at different levels of KE assaults?

While these questions are basic to all evidence-based targeting decisions, from cancer treatment to automobile safety, they are rarely addressed in a policing context. We present them as the first step in forecasting and targeting not only KE homicide, but also any kind of rare and highly harmful outcomes in policing. The same questions could be asked about targeting missing persons' investigations, or allocating special traffic speed enforcement to frequent crash zones. The answers to these four questions cannot tell police what to do, or even where to do it. Nonetheless, they are essential to making informed choices about how to balance the strengths and limitations of any course of action.

\section{Data}

Two main data sources were required for this analysis: the locations of KE homicides and the locations of KE assaults. The former was readily available. The latter posed substantial barriers and costs in classification. (Digitizing these data would be the first step for implementing this method of forecasting knife murders).

Underpinning both datasets is the Metropolitan Police Crime Reporting Information System (CRIS). The MPS records every allegation or instance of crime within CRIS; in doing so, a plethora of different data items is recorded by the reporting officer and the secondary investigating units. A selection of these data was extracted from the original database to construct a new, tabulated record of every single recorded homicide for the period 2008-2018 (using sequential, financial year periods). This included all forms of 
"culpable" homicide (i.e., manslaughter) but not attempts. Each homicide event then had appended to the weapon used.

Typological and demographical detail on the CRIS system is created initially by the first recording officer and later amended by the investigating unit if subsequent enquiries prove a particular code to have been missed or erroneously appended. For example, if a homicide were later discovered to be drug-related, a "flag" would be added to the crime report to this effect; these flags are the characteristic features of the event or victim that are absorbed into the dataset.

In addition, each homicide event, treated as a single unit of analysis, had affixed to it the corresponding geocoded location of the homicide (LSOA). In three of the 100 knifeenabled homicides in 2017/2018, the location of the stabbing could not be determined after the victim was admitted to hospital. Therefore, our analysis is based on all 97 of the $\mathrm{KE}$ homicides in which a geographic location of knife attack was recorded.

In a separate dataset, each of the 3543 nonfatal knife injury offenses in 2016/2017 was entered and their geographical locations were added. The initial data were derived from the CRIS database compiled by MPS police officers. Because a manual review [of text] was required to determine, in every case, whether an assault was knife-enabled and in which LSOA each KE assault occurred, it was only possible to code a single, most recent year's accessible data. These data were further transformed to make each LSOA a unit of analysis. Once these data had been extracted and collated, the corresponding homicide counts for both year 1 (2016-2017) and year 2 (2017-2018) were added to the KE assault data in year 1 in each corresponding LSOA.

For year 1 (2016/2017), only 3506 of the 3543 nonfatal knife injury offenses could be geocoded; for the rest, the location of the stabbing was not known. Further analysis revealed that 2048 different LSOAs were the locations for these 3506 nonfatal knife assaults. Thus, $42 \%$ of London's 4835 LSOAs experienced a knife assault in 2016/2017, while 97 (2\%) of the total 4835 had one or more homicides in 2017/2018.

\section{Limitations and Data Integrity}

Verification of CRIS data integrity was undertaken through reference to a separate computer database, the Home Office Large Major Enquiry System (HOLMES) - employed separately by investigators working within the Homicide and Major Crime Command. A (dip-sampled) cross-comparison of the same events as recorded in both CRIS and HOLMES was used to test whether a vital detail in CRIS was accurate, in 42 separate homicides, each selected randomly from the period. All 42 were found to hold the same typological and demographic data in HOLMES as the CRIS report of the same incident.

Each event can, of course, be given more than one categorical label. A knife-enabled homicide can equally be counted as a domestic/familial homicide or, likewise, a drug or gang-related homicide - if all of these characteristics are also present within the surrounding circumstances. For more details on data collection, see Massey (2018).

\section{Methods}

The primary method of this analysis is to compare all London LSOAs in the financial year 2016/2017 (year 1) to all LSOAs in 2017/2018 (year 2). By sorting each LSOA 
into different categories in each of the 2 years, the study was able to use year 1 coding to forecast year 2 patterns. The year 1 data combined all LSOA-specific frequencies from CRIS data listing knife-enabled serious assaults. The year 2 data on KE homicides were then assessed for risk levels in relation to whether each LSOA with a year 2 homicide had been coded for having had $0,1,2,3,4,5$, or 6 or more knife-enabled nonfatal injury attacks in year 1 .

We then computed the prevalence (in percent) of year $2 \mathrm{KE}$ homicides among LSOAs in each of the seven KE assault frequency categories in year 1 . The magnitude and differences in percentages were calculated in the simplest terms possible, to make the findings transparent to the widest possible audience for a dialog of police legitimacy (Bottoms and Tankebe 2012).

What is harder to explain to a wider audience is the difficult trade-off between the specificity and sensitivity of a forecasting tool (Yerushalmy 1947). The specificity of a prediction is defined as the true positive rate: what proportion of all predictions (or detections, as in cancer or other diseases for which tests are conducted on people) turn out to be accurate? (The false positive rate is derived by subtracting the true positive percentage from 100\%; see Table 2). The sensitivity of a prediction, in contrast, is the probability of a negative prediction being accurate: the true negative rate. (The true negative rate is derived by subtracting the false negative percentage from $100 \%$ ). In a perfect prediction, both positive and negative predictions would be $100 \%$ true. In practice, forecasting usually confronts an inverse relationship between true positives and true negatives: the higher the true positive rate, the lower the true negative rate. The more false positives a prediction avoids, the more false negatives it is likely to generate.

The method of presenting both specificity and sensitivity in comparison to each other (see Table 2 below) offers a more precise way of framing difficult resource allocation decisions for senior police leaders.

\section{Findings}

\section{Facts on the Context}

\section{Rising Homicides}

This study was undertaken in a period of rising total homicides in London, as displayed in Fig. 1.

The study period had an even more rapid increase in KE homicides, as shown in Fig. 2, with a $100 \%$ increase from 50 to $100 \mathrm{KE}$ homicides in 2016/2017 to 2017/2018, reaching a record high annual proportion over the decade of two thirds of total homicides (Fig. 3).

In the 10-year period to 2018, there were 590 knife-enabled homicides across London. As a proportion of the yearly total for all kinds of homicide, KE homicide showed some annual variation. Excluding the final year, the proportion of KEs ranged from a high rate of $57 \%$ of total to a low rate of $41 \%$ of total homicides. Where both figures align is at the point of the marked increase of both measures in the final year (see Massey 2018: Fig. 12 and appendix 3). As a raw total, there were $100 \mathrm{knife-}$ enabled homicides in 2017/2018, almost a $100 \%$ increase over all but one of the previous 10 years. 


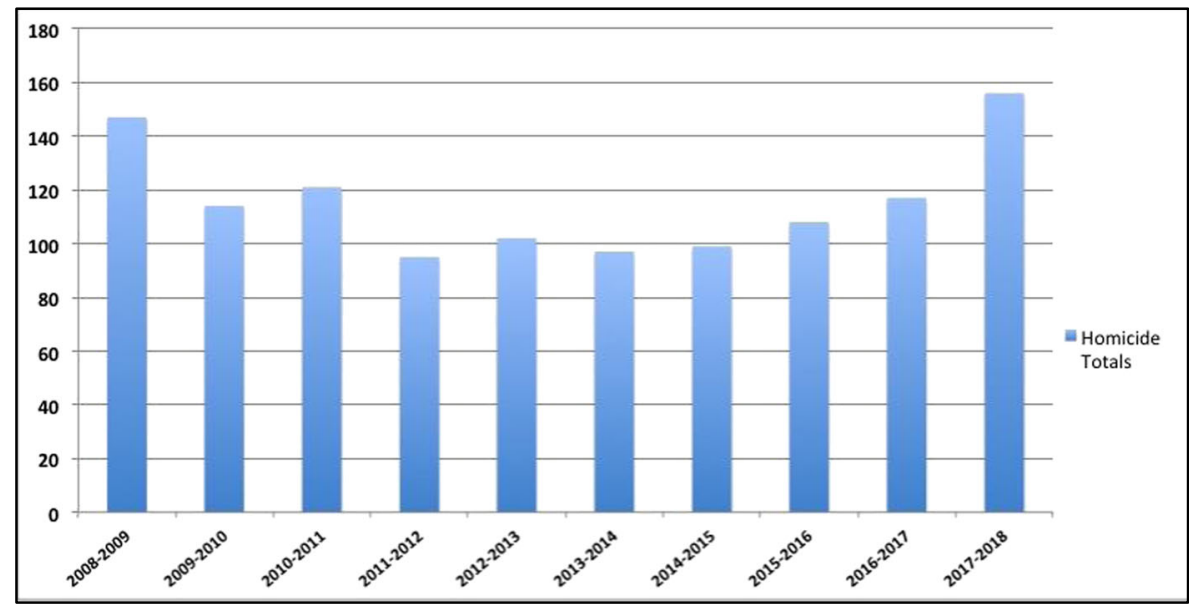

Fig. 1 Annual homicide totals in London, 2008-2018

\section{Not Mostly a Gang Problem}

The data contradict a widespread view that knife-enabled homicides are primarily gang-related. Over the 10-year period, only $21 \%$ of knife-enabled homicides were flagged by investigators as gang-related. In the final year, of the 100 knife-enabled homicides, 29 were gang-related, showing a clear increase, but with gang connections still a minority of all KE homicides. Conversely, however, when we reverse the analysis to determine what percentage of these gang-related homicides are knife-enabled, we see that a majority of gang homicides (59\%) are knife-enabled (Massey 2018: Figure 13).

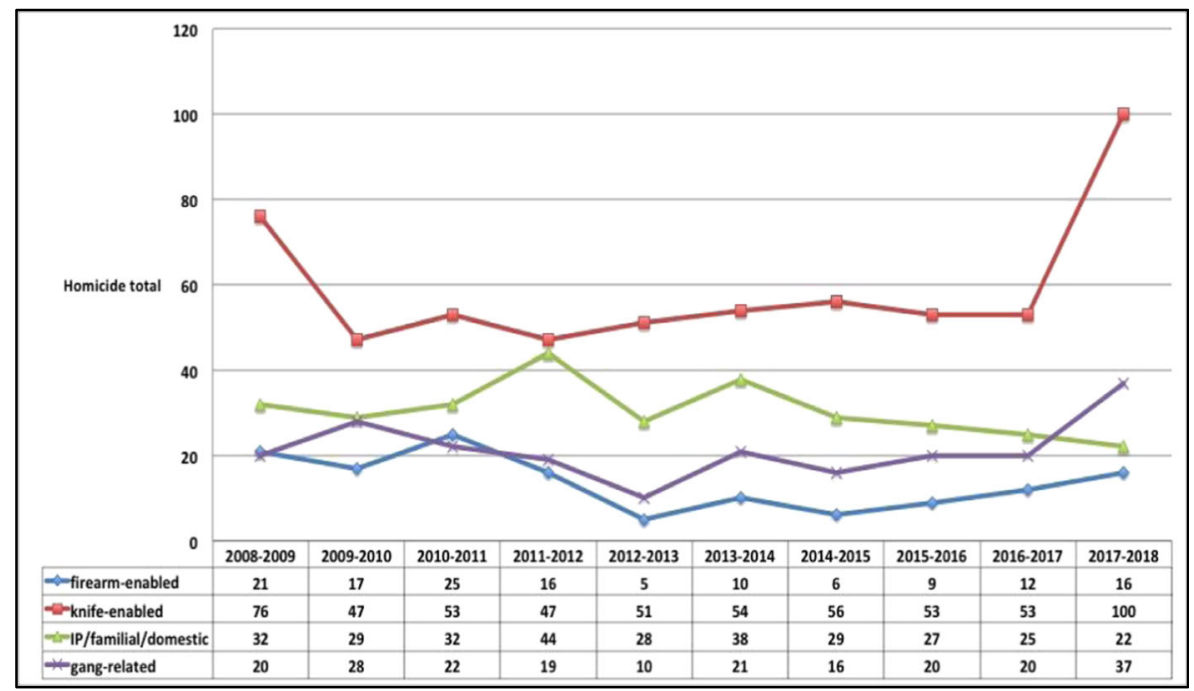

Fig. 2 Homicide trends by category, 2008-2018 


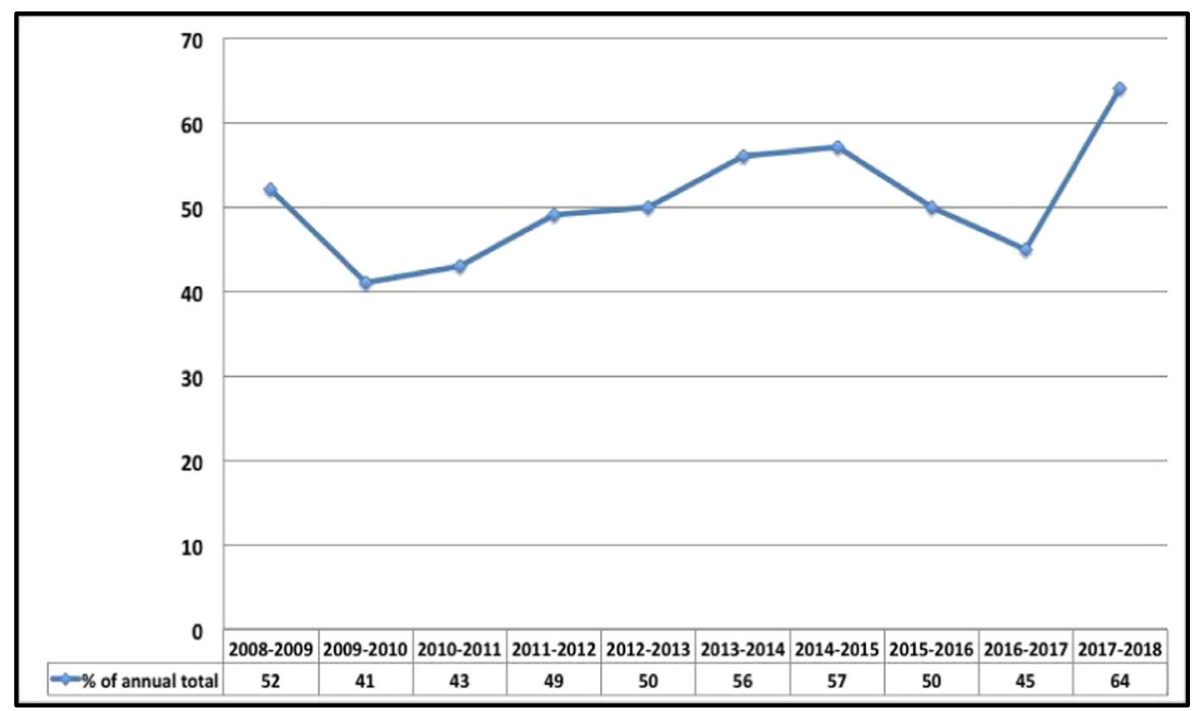

Fig. 3 Knife-enabled homicides as a proportion of the yearly total

\section{Minimal Concentration}

In the short run, the concentration of KE homicides in space appears to be relatively minimal, compared to robberies (Sherman et al. 1989) or to crime in general (Weinborn et al. 2017). Over 10 years, the 590 knife-enabled homicides were spread across in 523 LSOAs, which suggests a very low rate of any repetition of KE homicides (but not necessarily of KE woundings; see Table 1). Highlighting the LSOAs where over 10 years, two or more (knife-enabled) homicides occurred, shows the highest 57 LSOAs accounting for only 119 knife-enabled homicides. These findings suggest that KE homicide locations are dynamic rather than stable — and more likely to be predicted by other, more frequent types of crimes besides prior KE homicides, such as nonfatal knife assaults.

The top-ranked 151 LSOAs for nonfatal assaults show far more repetition in 1 year (2016/2017) than KE homicides show in 10 years. These top 151 accounted for 781 nonfatal knife assaults, a mean of over five knife injuries in 12 months. This nonfatal pattern creates a clear power few of $3 \%$ of LSOAs with $22 \%$ of all nonfatal knife assaults. Compared to the more general pattern of crime concentration (Weisburd 2015), nonfatal KE injury is far more similar to that power few pattern of concentration than is KE homicide.

\section{Moving Targets}

A geographical analysis (Massey 2018) also revealed movement of KE homicides from the first half of the 10-year period to the second; only one of the LSOAs that experienced a knife-enabled homicide in the first half also experienced a homicide in the second. This is suggestive of a moving power few LSOAs for knife homicides, which might well be anticipated by a moving pattern of nonfatal KE injuries. The pattern of movement is reinforced by the fact that boroughs experiencing the highest number of homicides changed substantially between in the first and second 5-year 
Table 1 Prevalence of LSOAs with KE homicide in year 2 by frequency of KE injury assaults in year 1

\begin{tabular}{|c|c|c|c|}
\hline $\begin{array}{l}\text { Number of nonfatal } \\
\text { knife-enabled assaults } \\
\text { per LSOA in year } 1 \\
(2016 / 2017)\end{array}$ & $\begin{array}{l}\text { Number of } \\
\text { LSOAs in each } \\
\text { category of } \\
\text { year } 1 \\
\text { frequency }\end{array}$ & $\begin{array}{l}\text { Number of LSOAs } \\
\text { in this group with } \\
1 \text { or more knife-enabled } \\
\text { homicides in year } 2 \\
(2017 / 2018)\end{array}$ & $\begin{array}{l}\text { Percent of LSOAs } \\
\text { with a year } 2 \text { homicide } \\
\text { within each year } 1 \\
\text { injury category of } \\
\text { LSOAs }\end{array}$ \\
\hline 0 & 2781 & 30 & 1.1 \\
\hline 1 & 1258 & 28 & 2.2 \\
\hline 2 & 454 & 20 & 4.4 \\
\hline 3 & 186 & 7 & 3.8 \\
\hline 4 & 74 & 3 & 4.1 \\
\hline 5 & 35 & 3 & 9 \\
\hline 6 & 14 & 1 & 7 \\
\hline 7 & 10 & 2 & 20 \\
\hline 8 & 8 & 2 & 25 \\
\hline 9 & 4 & 0 & 0 \\
\hline 10 & 3 & 1 & 33 \\
\hline 12 & 1 & 0 & 0 \\
\hline 14 & 1 & 0 & 0 \\
\hline
\end{tabular}

periods analyzed. From three adjoining south-central London boroughs in the first half of a decade, the highest incidence of homicide has moved to the far north, east, and west of the capital within the period (see Massey 2018: Figs. 15-18).

\section{Short-Term Correlation}

Despite the dynamic nature of KE injury and homicide locations, over the 2-year period of our analysis, the injury locations appear to match the homicide locations. This correlation may be visualized by comparing the mapped distribution of year 1 (2016/2017) KE injuries by Ward in Fig. 4 to the LSOA prevalence of KE Homicides in year 2 (2017/2018) in Fig. 5. This fact sets the stage for answering the four key research questions.

\section{Findings: Four Research Questions}

1. Does the prevalence of KE homicide across LSOAs in 1 year (year 2) predictably increase from lower to higher frequencies of KE assaults in an LSOA in the prior year (year 1)?

Yes, the evidence shows a strong predictive relationship between the number of KE injury assaults in LSOAs in year 1 and the $N$ of KE homicides in year 2. Table 1 displays the full range of categories of year $1 \mathrm{KE}$ injury frequencies in relation to the prevalence of KE homicides in year 2. Figure 6 shows the percentage of LSOAs with year $2 \mathrm{KE}$ homicides across a combined set of just seven of the year 1 assault frequency categories displayed in Table 1. 


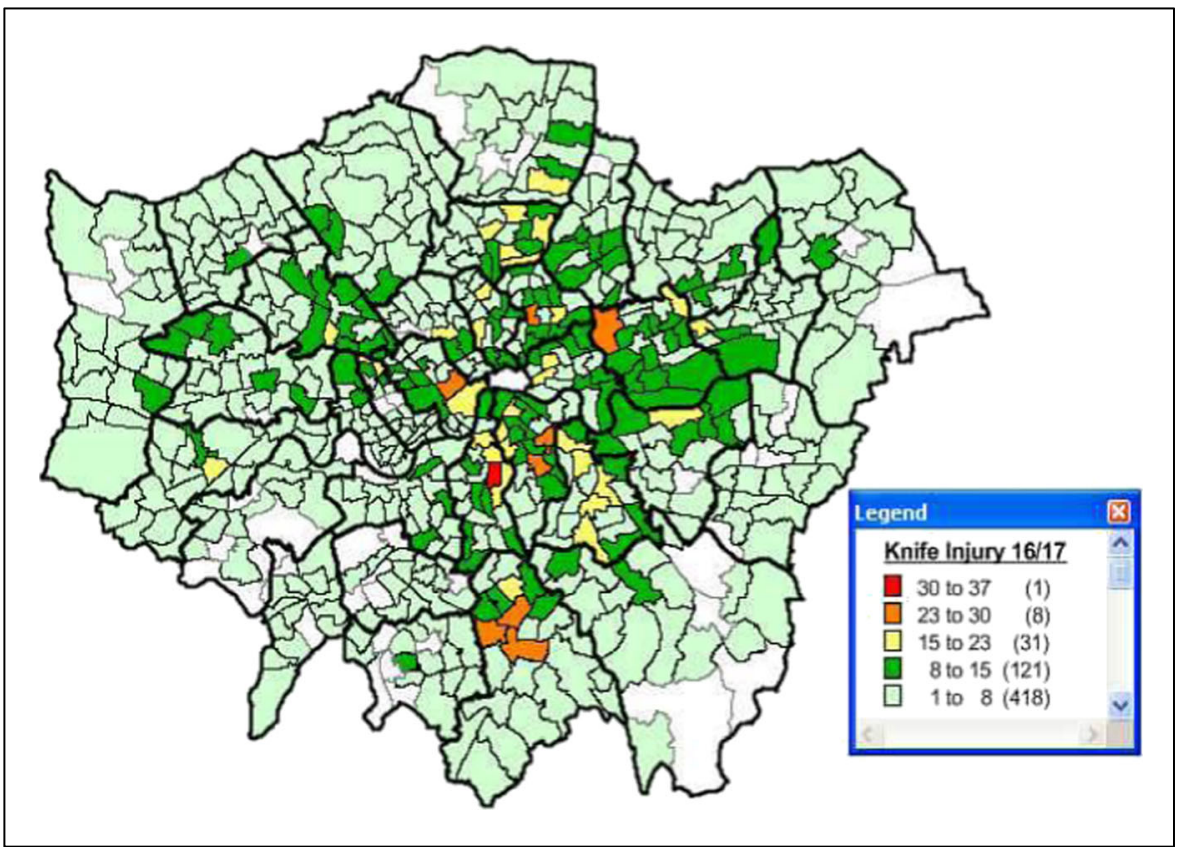

Fig. 4 Knife-enabled injury frequency by Ward across London, 2016/2017

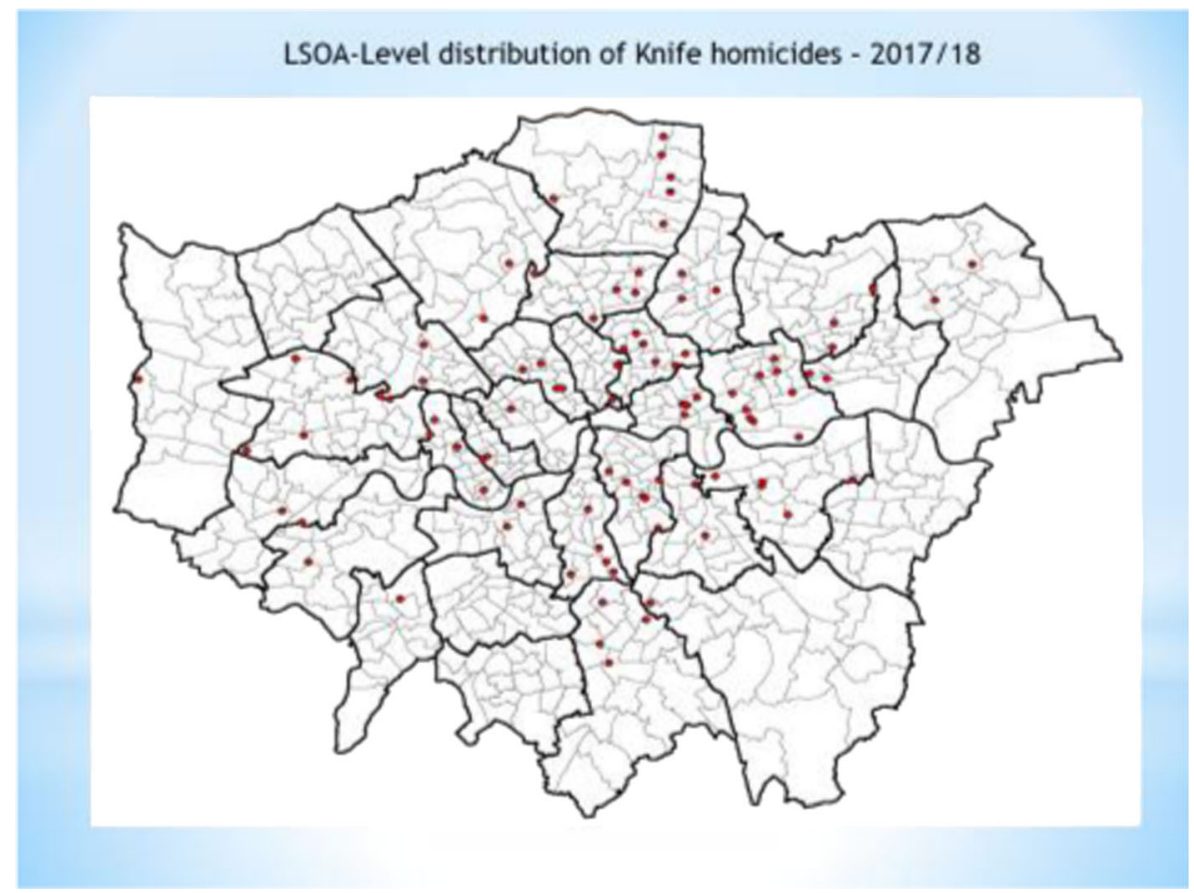

Fig. 5 Knife-enabled homicide prevalence by LSOA, 2017/2018 


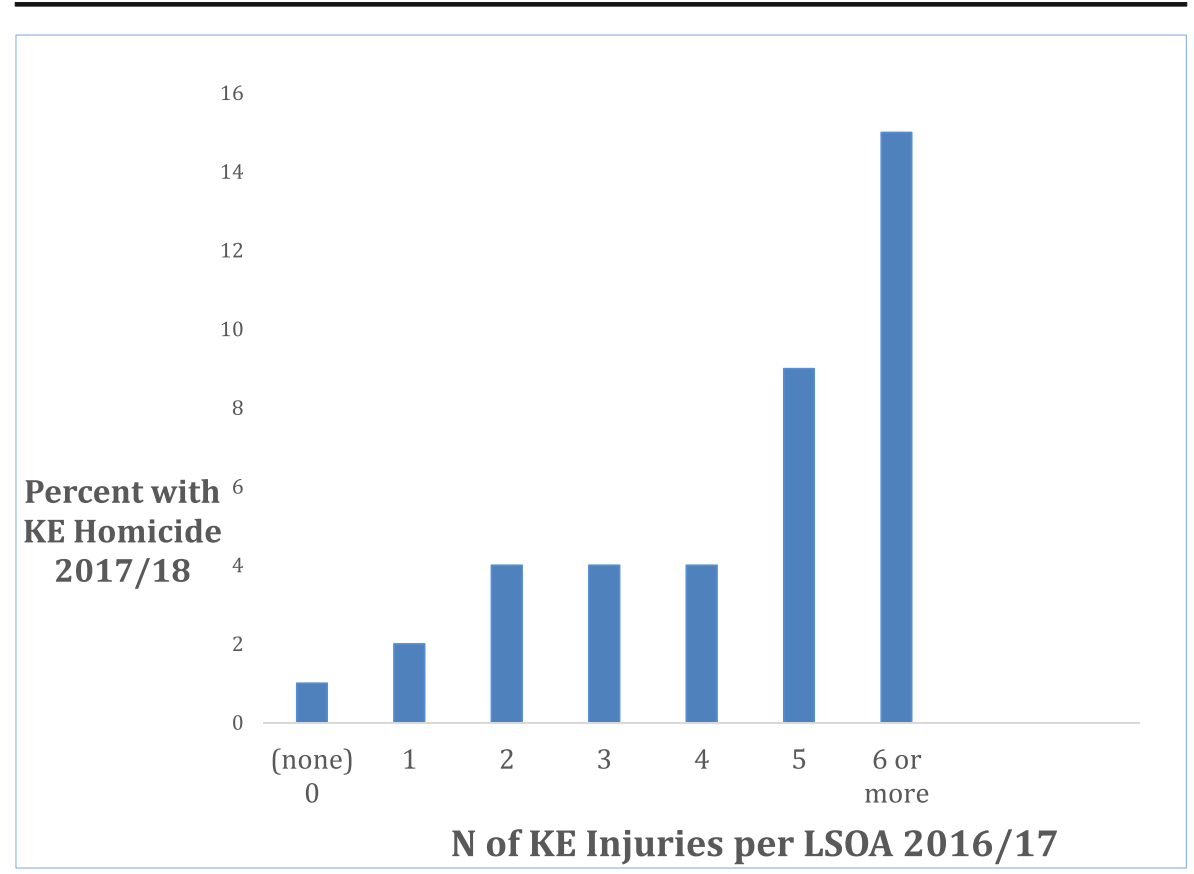

Fig. 6 Percent of LSOAs with year 2 knife-enabled homicide by frequency of year 1 knife-enabled criminal injury

Figure 6 shows that the more near-miss KE injuries occur in an LSOA, the greater the risk of KE homicides. The difference in risk levels does not appear as a fluke in an otherwise random pattern. In a progression of increases in KE homicide risk from 1 to $15 \%$, the broad pattern is clear: the more prior nonfatal KE injuries over the previous 12-month period, the higher the risk of KE homicides in the next year. (No test of statistical significance is required since the data comprise a universe, not a sample).

This pattern is made all the stronger for what it does not contain: it is not a rolling 12month period between nonfatal assaults and a rolling monitoring period for KE homicides. It would be better to conduct the analysis that way if the digital resources become available. As presented, Table 1 lacks data on how much time elapsed between the end of the year 1 baseline measure of nonfatal KE injuries and the date of the KE homicide. That fact is unavoidable in the present analysis, for which nonfatal events were identified by humans reading thousands of crime reports. Were those data to be converted to digital coding at the point of crime reports entered into the CRIS system, there could be a more precise analysis linking a defined (but rolling) 365-day period for counting nonfatal KE injuries into a 365day follow-up period for monitoring KE homicide. Such a digital system could also stabilize the estimates with larger datasets, especially at the highest risk levels in the top 41 LSOAs, in which the $N$ of KE homicides in the numerator drops to only 6 (see Table 1). Nonetheless, at the highest levels of non-fatal knife crime, the predicted risk of homicide in the next year rose to $33 \%$ (Table 1). With a rolling digital 365-day forecast, it is possible that risk levels that high could be reliably identified.

2. How much higher is the highest risk level for KE homicide compared to the lowest risk level, in terms of the likelihood that any KE homicide occurs in year 2? 
As Fig. 6 shows, there is a large difference in the 2017/2018 risk of KE homicides between the 41 LSOAs that had six or more KE injuries the year before and the 2871 LSOAs that had no KE injuries the year before. While the risk of KE homicides is not zero anywhere in London, in most places (especially where no previous knife assault injuries have recently occurred), the homicide risk is only a tiny fraction of the risk at the highest levels of prior-year injuries. The highest risk level, based on nonfatal assaults, is 15 times higher than the lowest.

While the difference from the lowest (1\% KE homicide risk) to the highest (15\% KE homicide risk) may appear to be small in absolute terms, it is a very large increase in relative terms. It not only means that there is a $15 \%$ chance of a KE murder in areas that may normally receive no more patrol than adjoining areas of $1 \%$ risk. It also means that relative to other areas that police could target for homicide prevention, these areas are over $1400 \%$ more likely to have a murder than most LSOAs in London. The events remain rare for individuals. But for police, a target with a clearly identified $15 \%$ risk of any homicide is also a rare event, usually prompting substantial investments in protection. This clarity, of course, could be strengthened by replications of the analysis within London for other time periods, as well as in other UK cities.

3. What is the level of "sensitivity" or true positive homicide prediction rate from a decision to target LSOAs with extra policing resources at different levels of KE assaults?

4. What is the level of "specificity" or true negative rate from a decision to target LSOAs with extra policing resources at different levels of KE assaults?

Table 2 presents the data that answers these questions. In sum, there is not much difference in specificity, or false positive rates, between targeting only the highest risk LSOAs, on the one hand, and targeting all LSOAs that had any prior nonfatal KE injuries in year 1, on the other (Table 2, column D); both are in the high $90 \%$ false positive range. Nor is there much difference in true negative rates between not targeting the 4794 areas that had five or fewer KE injuries and not targeting 2787 that had zero $\mathrm{KE}$ injuries in year 1 (Table 2, column C). High rates of false positives and true negatives are the result no matter which level of risk targeting is examined.

To make this analysis transparent, we describe the formula for calculating the percent of true negatives: subtract the $N$ of homicides likely completed (column $\mathrm{G}$ in Table 2) from the $N$ of LSOAs not targeted (column $\mathrm{C}$ in Table 2) and divide the

Table 2 False positives and false negatives at each risk level selected for targeting

\begin{tabular}{lllllll}
\hline $\begin{array}{l}\text { A. LSOA } \\
\text { risk of KE } \\
\text { homicide }(\%)\end{array}$ & $\begin{array}{l}\text { B. Number } \\
\text { of LSOAs } \\
\text { targeted }\end{array}$ & $\begin{array}{l}\text { C. Number } \\
\text { of LSOAs } \\
\text { not } \\
\text { targeted }\end{array}$ & $\begin{array}{l}\text { D. \% of } \\
\text { targets false } \\
\text { positives } \\
\text { [sensitivity] }\end{array}$ & $\begin{array}{l}\text { E. \% of } \\
\text { nontargets } \\
\text { true } \\
\text { negatives } \\
\text { [specificity] }\end{array}$ & $\begin{array}{l}\text { F. Maximum } \\
\% \text { of } \\
\text { homicides } \\
\text { prevented }\end{array}$ & $\begin{array}{l}\text { G. Likely } \% \\
\text { of homicides } \\
\text { completed, } \\
(N)\end{array}$ \\
\hline $15 \%$ & 41 & 4794 & 85 & 98 & $6 / 97=6 \%$ & $94(93)$ \\
$12 \%$ & 76 & 4759 & 91 & 98 & $9 / 97=9 \%$ & $91(88)$ \\
$5 \%$ & 790 & 4045 & 96 & 99 & $39 / 97=40 \%$ & $60(58)$ \\
$3 \%$ & 2048 & 2787 & 98 & 99 & $67 / 97=69 \%$ & $31(30)$ \\
$1 \%$ & 4835 & 0 & 99 & - & $97 / 97=100 \%$ & $(0)$ \\
\hline
\end{tabular}


difference by the $N$ of LSOAs not targeted (also column $\mathrm{C}$ of Table 2). The formula for false positives is similar: subtract the $N$ of maximum homicides prevented (Table 2, column F) from the $N$ of LSOAs targeted (column B) and divide the difference by the $N$ of LSOAs targeted (Table 2, column B).

What matters most for policing, however, is some measure of available resources. That is certainly a matter for testing. But, it is also a matter that is informed by the results in Table 2. What matters most in police decisions is not the rates of false negatives, but the absolute number - especially for homicides. Hence, the discussion of Table 2 in policing terms would likely place special emphasis on columns F and G.

These columns present commanders with five scenarios. The first is presented in the bottom row of the table: to assign equal levels of KE homicide prevention across London. That would guarantee that something has been done to stop every potential $\mathrm{KE}$ homicide. It could also guarantee that very little can be done anywhere, including the highest risk areas, because London is so large.

The next targeting scenario (see Fig. 7) is presented in the second row up from the bottom: invest heavily in all LSOAs with any KE injuries in the preceding 12 months. That choice would, perhaps block by block, direct officers to focus on less than half of the LSOAs in London (2048 out of $4835=42 \%$ ). By minimally investing in the $58 \%$ of LSOAs with the lowest risk, police resources could have targeted $69 \%$ of all KE

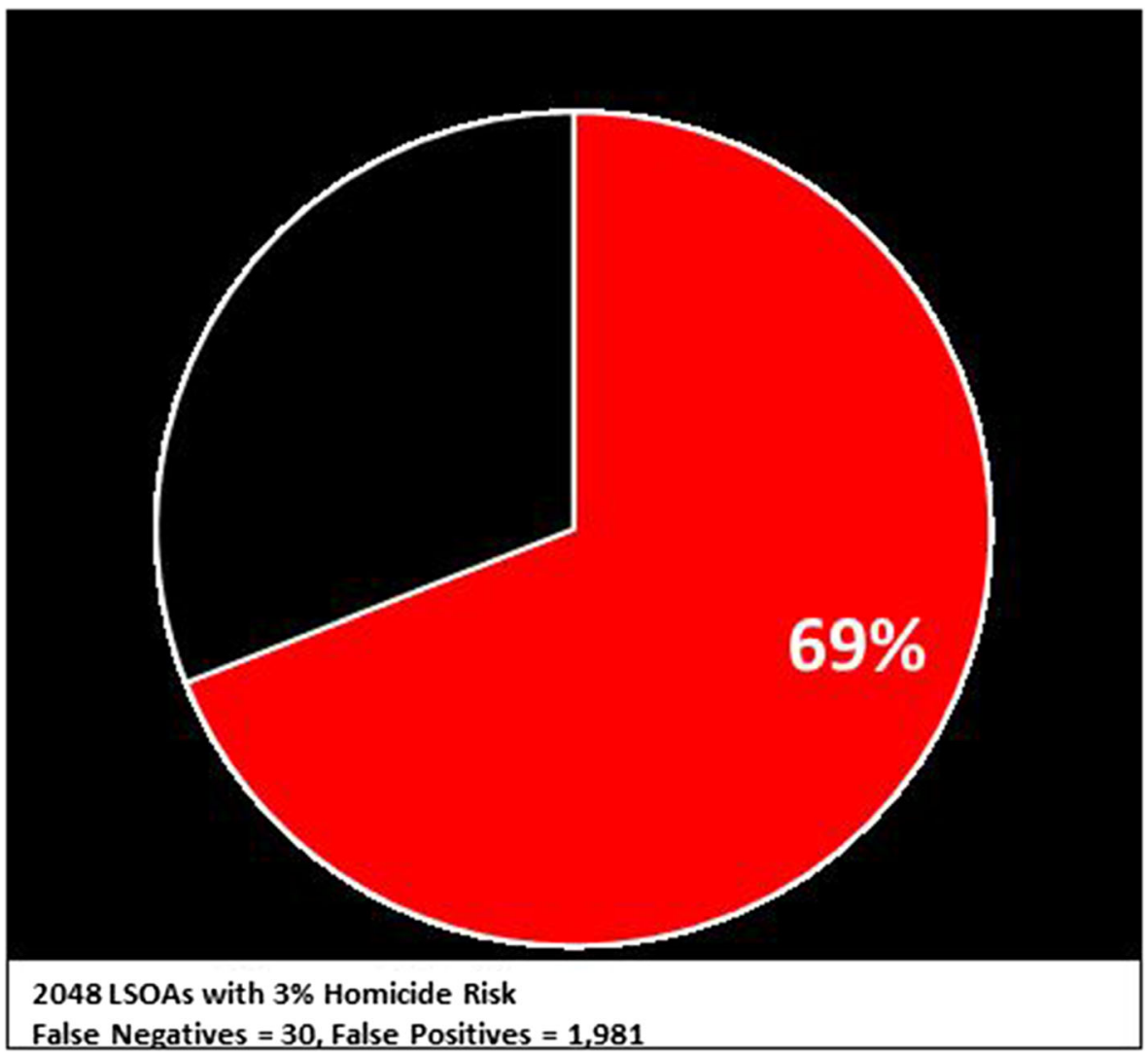

Fig. 7 Percent of homicides potentially prevented by targeting all 2048 areas with prior stabbing 


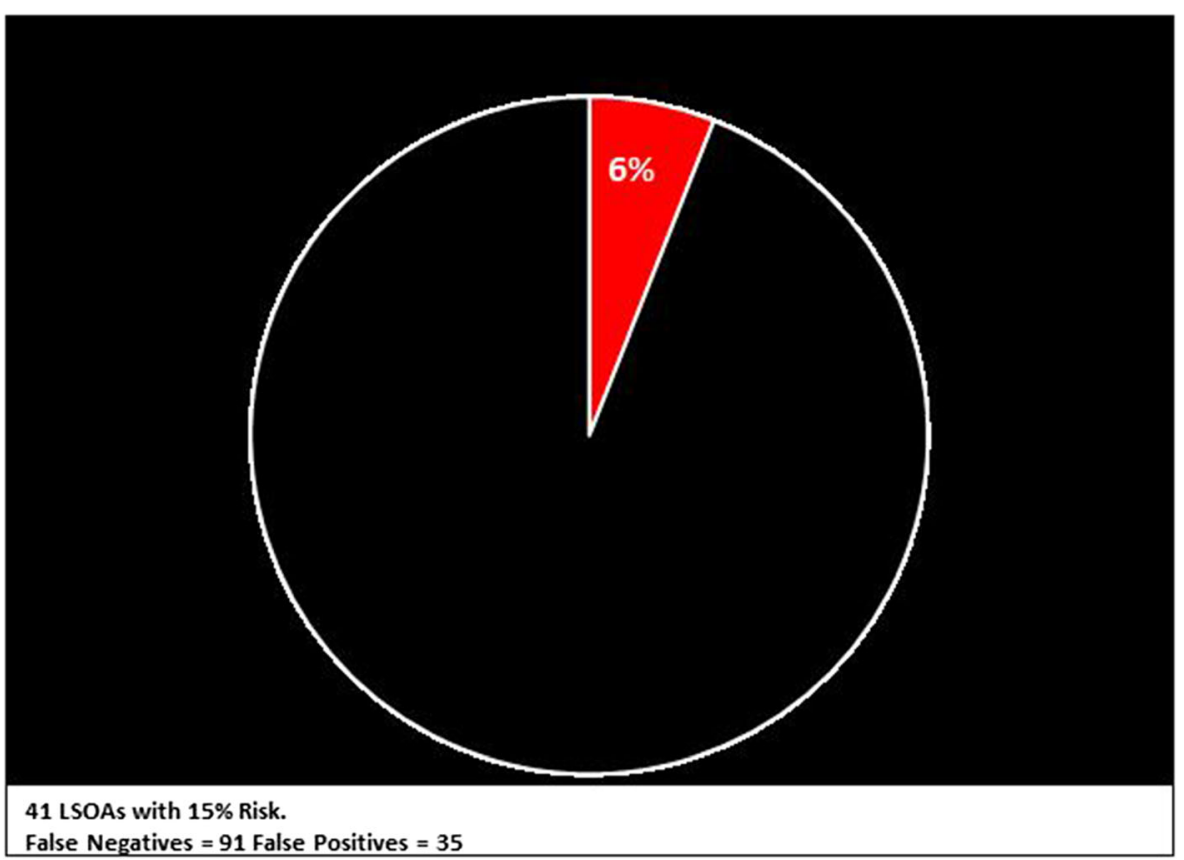

Fig. 8 Maximum percent of homicides prevented by targeting all 41 highest-risk areas

homicides in $2017 / 2018$, or 67 out of 97 . Yet, that leaves $30 \mathrm{KE}$ homicides that are not addressed in the same way. And while the rate of false negatives is very low across those thosuands of LSOAs not receiving extra resources (only 1\%), the absolute number of 30 murders is very high in a London context.

Figure 8 displays the targeting scenario in which police concentrate most heavily on the LSOAs that have the highest level of risk of knife homicide (15\%). This is by far the most efficient use of police resources. It is also the least effective, if it attracts $100 \%$ of available resource. Even if that prevented $100 \%$ of the murders in those areas, that would prevent only $6 \%$ of all KE homicides. Thus, merely targeting the very highest risk levels does not seem to be a viable strategy.

Much would depend, of course, on resource availability, and perhaps even the competing priorities within each of the 12 basic command units. Yet, the highest risk areas would be given priority at a cost of an even higher absolute count of false negatives. If a commander wished to give very high levels of investment to the 41 highest LSOAs, where the risk of KE homicide is $15 \%$, that strategy would only prevent a maximum of six homicides. That is why these data are best used to inform a targeting strategy. They certainly cannot speak for themselves.

\section{Conclusions}

What many police commanders might do with these findings is to make a graduated allocation of resources. With three or four different levels of investment guided by the risk forecasts, commanders could guarantee that every LSOA would get some level of 
preventive policing against knife crime. Yet, they could also guarantee that the greatest investment in prevention could be targeted on the LSOAs with the greatest risk, where the chances of prevention are greatest and target areas are smallest in number.

To the extent that this study becomes a first step towards an automated digital policing system, there is a potential for treating preventive policing much like reactive response policing. If nonfatal stabbing occurs in an LSOA - and perhaps the third stabbing in 3 months (or what would more predicably happen with 3 stabbings in 3 days or even three hours) - a high-risk level for that LSOA could be declared. Intensive policing, at least for a short period of time, could lead to greater risk of concealed weapons being detected. Arrests could increase for absconded persons in the LSOA. Focused deterrence on knife carrying could become highly visible. If a digital analysis shows that after several months, or even weeks or days, that the risk of KE homicide has declined, the resources invested in preventing KE homicide in that area could be reallocated to other areas that have recently received a high-risk-of-homicide forecastperhaps defined as any short-term level of over $10 \%$ chance of a homicide.

A transparently calculated level of KE homicide risk could even become the basis for a special authorization of police powers to use stop and search within the very confined area of an LSOA. This idea would likely require a substantial dialogue with local communities in order to gain legitimacy. Yet, the evidence supporting such a decision would at least be clear-unlike qualitative intelligence that can often not be divulged as to its source nor transparently examined for its reliability.

Regardless of what commanders might do with these findings, the most important policy implication of this analysis is that it is now operationally out of date: not the research method, that is, but the specific lists of high-risk LSOAs. The analysis has shown that these data and methods can forecast KE homicide risk with known rates of error, in specificity and sensitivity. But, it is by definition a short-term analysis. The case for digital policing is that a computer program can automatically run the same analysis every day, or even several times a day, to present the most accurate forecasts on the most up-to-the minute datasets.

The brute fact is that such analysis is not possible under current IT systems in England. The digital category of nonfatal knife injury by assault, to our knowledge, does not exist in police records for England and Wales. It is only by manual labor that this analysis was made possible. We recommend that crime recording systems be altered as soon as possible to allow a keystroke by the reporting officer to indicate the occurrence of a KE injury in any legal category of crime. Then and only then can the relevant data be accessed in real time to use twenty-first-century data analysis to forecast when and where these murders are most likely to occur-and most likely be preventable.

In broad strategic terms, a quintessentially utilitarian approach is indicated: police leaders could deploy greater resources to the power few LSOAs to address the most significant proportion of crime harm, achieving the greatest benefit for the largest section of the community. LSOAs are small in size, few in number, and can be targeted by regular, high visibility patrols. BCU-level data processing can calculate up-to-date analysis at the LSOA level to reveal their most recent, vulnerable to KE homicide locations.

Such patrols do currently take place but are often deployed across whole boroughs for short, isolated periods. This research has clearly demonstrated that LSOA geocodes can be ascribed to a larger volume of knife-enabled, nonfatal assaults, providing police leaders with more precise targeting data to assign hotspot patrols. This permanent, concentrated, LSOA-level analytic focus would yield its own invaluable local 
intelligence, help identify emerging mobility patterns, and fuel the evidence-led approach. Nor is it likely that targeting police actions so tightly would merely displace the offenses elsewhere (Mazeika 2014; Weisburd et al 2006).

In more specific terms, this geographical understanding can inform a myriad of different preventative as well as enforcement initiatives. Isolating the most vulnerable areas allows more selective targeting, for example, of schools, with additional resources such as physical safeguarding measures. These might include journey-to-school chaperones; knife arches at school entries; closer monitoring of pupil exclusions, internal peer-relationships, and gang affiliations; and greater local authority and police oversight upon specific vulnerable youths. Thus, preventative targeting of LSOAs could lead to community partnership measures as well as extra patrol activity.

Accordingly, a multi-agency board overseeing locally accountable multi-agency teams, dedicated to designing and implementing preventative intervention programs, is well worth testing as evidence-based policing (Sherman 2013). By combining expertise with specific LSOA-level knowledge, a more preventative outlook can be attained. The achievability of such a proposal is underscored by the plethora of such multi-agency groups that already exist for retrospective homicide assessment. By forecasting KE homicide risk, digital policing could encourage prospective multiagency action in very local areas.

Provided further EBP principles of tracking and testing were employed, the success or failure of these actions could be readily captured for ongoing data analysis. Targeting is only the first step to better knowledge of what works to prevent murders. Testing and tracking alternative responses to digital policing forecasts is needed for the long run. At the same time, targeting itself can be improved by continuing to build more data into a forecasting model. This study is a first step towards making that investment. So far, the evidence suggests that investment could reap substantial dividends.

Acknowledgements We are grateful for the support of Metropolitan Police Service Commissioner Cressida Dick in encouraging research of this kind. The first author also thanks Chris Sims for his support during the Cambridge course of 2017-2018, and Roy Baker, Claire Durnell, Christine Leist, and Richard Moore; the latter's statistical contribution was invaluable.

Open Access This article is distributed under the terms of the Creative Commons Attribution 4.0 International License (http://creativecommons.org/licenses/by/4.0/), which permits unrestricted use, distribution, and reproduction in any medium, provided you give appropriate credit to the original author(s) and the source, provide a link to the Creative Commons license, and indicate if changes were made.

\section{References}

Bottoms, A. (2012). Developing socio-spatial criminology. In M. Maguire, R. Morgan, \& R. Reiner (Eds.), The Oxford handbook of criminology (5th ed., pp. 450-488). Oxford: Oxford University Press.

Cohen, L. E., \& Felson, M. (1979). Social change and crime rate trends: a routine activity approach. Am Sociol Rev, 44(4), 588-608.

Cohen, J., \& Ludwig, J. (2003). Policing crime guns. In J. Ludwig \& P. J. Cook (Eds.), Evaluating gun policy: Effects on crime and violence (pp. 217-239). Washington DC: Brookings Institution.

Dick, C. (2018). The future of policing in the digital age. Ditchley: Ditchley Foundation. https://www.ditchley. com/future-policing-digital-age. 
Jackson, M. (2010). Homicide concentration and distribution patterns in London an exploratory analysis of ten years of data (Unpublished MSt thesis, Police Executive Programme, Institute of Criminology, University of Cambridge).

Koper, C. S., \& Mayo-Wilson, E. (2006). Police crackdowns on illegal gun carrying: A systematic review of their impact on gun crime. Journal of experimental criminology, 2(2), 227-261.

Massey, J. (2018). Targeting the Geography and Demography of Recent Homicide Trends in London: An Exploratory Analysis. M.St. Thesis, Police Executive Programme, Institute of Criminology, University of Cambridge.

Mayhew, P., Clarke, R. V. G., Sturman, A., \& Hough, J. M. (1976). Crime as Opportunity. Home Office Resesarch Study No. 34. London: HMSO.

Mazeika, D. (2014). General and specific displacement effects of police crackdowns: criminal events and "local" criminals. PhD diss. Department of Criminology and Criminal Justice, University of Maryland.

McGarrell, E. F., Chermak, S., Weiss, A., \& Wilson, J. (2001). Reducing firearms violence through directed police patrol. Criminology \& Public Policy, 1(1), 119-148.

Mohler, G. (2014). Marked point process hotspot maps for homicide and gun crime prediction in Chicago. Int J Forecast, 30(3), 491-497.

Moore, M. H. (1980). The police and weapons offenses. ANNALS AAPSS, 452(1), 22-32.

Office for National Statistics (2011) Retrieved 20 April 2018, from ONS:https://www.ons.gov. uk/methodology/geography/ukgeographies/censusgeography\#super-output-area-soa

Office of National Statistics (2019) Retrieved 9th March 2019 from https://data.london.gov.uk/dataset/lsoaatlas

Rosenfeld, R., Deckard, M. J., \& Blackburn, E. (2014). The effects of directed patrol and self-initiated enforcement on firearm violence: A randomized controlled study of hot spot policing. Criminology, 52(3), 428-449.

Sherman, L. W. (2013). 'The rise of evidence based policing': targeting, testing and tracking. In M. Tonry (Ed.), Crime and justice in America, 1975-2025, crime and justice: a review of research, vol. 42 (pp. 377451). Chicago: University of Chicago Press.

Sherman, L. W., Gartin, P., \& Buerger, M. (1989). Hot spots of predatory crime: routine activities and the criminology of place. Criminology, 27(1), 27-55.

Sherman, L. W., Rogan, D. P., Shaw, J. W., \& Rogan, D. P. (1995). The Kansas City Gun Experiment. Research in Brief. Washington, DC: U.S. National Institute of Justice.

Sutherland, J. \& Muller-Johnson, K. (2019). Evidence vs. Professional Judgment in Ranking "Power Few" Crime Targets: A Comparative Analysis. Cambridge Journal of Evidence-Based Policing, 3.

Villaveces, A., Cummings, P., Espitia, V. E., Koepsell, T. D., McKnight, B., \& Kellermann, A. L. (2000). Effect of a ban on carrying firearms on homicide rates in 2 Colombian cities. JAMA, 283(9), 1205-1209.

Weinborn, C., Ariel, B., Sherman, L. W., \& O’Dwyer, E. (2017). Hotspots vs. harmspots: shifting the focus from counts to harm in the criminology of place. Appl Geogr, 86, 226-244.

Weisburd, D. (2015). The law of crime concentration and the criminology of place. Criminology, 53(2), 133157.

Weisburd, D., Wyckoff, L. A., Ready, J., Eck, J. E., Hinkle, J. C., \& Gajewski, F. (2006). Does crime just move around the corner? A controlled study of spatial displacement and diffusion of crime control benefits. Criminology, 44(3), 549-592.

Wellford, C. F., Pepper, J., \& Petrie, C. (2005). Firearms and violence: a critical review. Washington: National Academies Press.

Wilson, J. Q. (1980). What can the police do about violence? ANNALS AAPSS, 452(1), 13-21.

Yerushalmy, J. (1947). Statistical problems in assessing methods of medical diagnosis with special reference to x-ray techniques. Public Health Rep, 62(2), 1432-1439.

Zimring, F. E. (1968). Is gun control likely to reduce violent killings? University of Chicago Law Review, 35 , $721-737$.

Publisher's Note Springer Nature remains neutral with regard to jurisdictional claims in published maps and institutional affiliations. 
John Massey, M.A. (Oxon), M.St. (Cantab) is a Detective Chief Inspector, Homicide and Major Crime Command, Metropolitan Police Service, London. The present article is based on data from his Cambridge MSt Thesis, which was supported by the Metropolitan Police Service.

Lawrence W. Sherman, M.A. (Cantab), Ph.D. is Professor and Chair of the Cambridge Police Executive Programme, Distinguished University Professor at the University of Maryland, and Editor-in-Chief of the Cambridge Journal of Evidence-Based Policing.

Timothy Coupe, M.A. (Oxon), Ph.D. is a Lecturer in Criminal Justice in the Cambridge Police Executive Programme, Institute of Criminology, University of Cambridge.

\section{Affiliations}

\section{John Massey ${ }^{1} \cdot$ Lawrence W. Sherman $^{2,3} \cdot$ Timothy Coupe $^{2}$}

Lawrence W. Sherman

Lawrence.Sherman@crim.cam.ac.uk

1 Metropolitan Police Service, London, UK

2 Institute of Criminology, University of Cambridge, Cambridge, UK

3 University of Maryland, College Park, MD, USA 